\title{
Nephronectin (NPNT) and the prediction of nephrotic syndrome response to steroid treatment
}

\author{
Mona Mohamed Watany $\mathbb{1}^{1} \cdot$ Hemat El-Sayed El-Horany ${ }^{2}$
}

Received: 24 October 2017 / Revised: 15 February 2018 / Accepted: 8 May 2018 / Published online: 11 June 2018

(c) European Society of Human Genetics 2018

\begin{abstract}
Steroid-resistant nephrotic syndrome represents about 10-20\% of pediatrics' nephrotic syndrome. The regeneration of glomerular barrier seems pivotal for cessation of proteinuria. Nephronectin (NPNT) plays a major role in nephrogenesis, signal transduction, and epithelial-mesenchymal interactions. This study aims to preliminary assess NPNT as potential noninvasive biomarker of glomerular regeneration and its ability to identify steroid resistance. In this case control study, 80 retrospectively selected patients with nephrotic syndrome were enrolled in addition to 40 healthy controls. Forty patients were steroid sensitive (SSNS) and the other 40 patients were steroid-resistant (SRNS), NPTN concentration was measured using ELISA and NPNT mRNA expression was assayed using real-time PCR. NPTN concentrations were significantly higher in SSNS than both SRNS and controls (The means were 4.64 $\pm 3.05,0.69 \pm 0.44$, and 1.63 \pm 0.59 , respectively). Moreover, NPTN concentrations were significantly lower in SRNS than controls. NPTN was significantly overexpressed in SSNS compared to both SRNS and controls (the means were $10.82 \pm 7.39,1.19 \pm 0.94$, and $1.04 \pm 0.10$, respectively) with no statistically significant difference between SRNS and controls. ROC curves analysis showed that both NPNT expression and NPNT serum level are of promising diagnostic performance ( $\mathrm{ROC}_{\mathrm{AUC}} 0.948$ and 0.896 , respectively). Regression analysis showed that both NPNT expression and NPNT serum level can be independent predictors of steroid resistance. The present study shows for the first time an enhanced expression of NPNT in steroid-sensitive nephrotic syndrome patients suggesting NPNT as a marker of glomerular regeneration. Also, serum NPNT can be a useful noninvasive biomarker of steroid resistance.
\end{abstract}

\section{Introduction}

Nephrotic syndrome (NS) is a syndrome characterized by increased glomerular filtration barrier permeability. It classically presents with heavy proteinuria (Urine protein excretion $>50 \mathrm{mg} / \mathrm{kg} /$ day or a spot urine sample with albumin/creatinine ratio (UACR) greater than $3 \mathrm{~g} / \mathrm{g}$ creatinine), hypoalbuminemia (serum albumin $<3 \mathrm{~g} / \mathrm{dL}$ ), edema, and hyperlipidemia. The majority of children who present with NS have minimal change disease (MCD) which is

Mona Mohamed Watany

mona.watany@med.tanta.edu.eg

monawatany@gmail.com

1 Clinical Pathology Department, Faculty of Medicine, Tanta University, Tanta, Egypt

2 Medical Biochemistry Department, Faculty of Medicine, Tanta University, Tanta, Egypt generally responsive to steroid therapy [1]. Hence, empirical steroid therapy is given to children who present with idiopathic NS. However, $\sim 10-20 \%$ of patients fail to respond to initial steroid treatment and are termed to have steroid-resistant nephrotic syndrome (SRNS) [2]. The consensus guidelines are to define steroid resistance by persistence of proteinuria after 6 weeks of steroid treatment with daily prednisolone $60 \mathrm{mg} / \mathrm{m}$, twice a day [3].

SRNS is a chronic progressive disorder affecting about $10 \%$ of all children with NS. Long term aggressive therapy with combinations of steroids, cyclosporine and alkylating agents like cyclophosphamide may cause complete or partial remission in $20-80 \%$ patients. Also, non-specific renal protective agents such as the ACE (angiotensin converting enzyme) inhibitors, angiotensin-2 receptor blockers, and anti-lipid agents can help to retard disease progression [4].

The glomerular filtration barrier is composed of inner endothelial layer and outer podocyte layer with the basement membrane and extracellular matrix (ECM) inbetween. The interaction between those cells and the 
surrounding ECM is essential to maintain the barrier functions of the glomerulus [5]. This interaction is mediated through integrin receptors that are trans-membrane glycoproteins of heterodimeric structure consisting of $\alpha$ and $\beta$ subunits [6].

Nephronectin is a tissue-specific and developmentally regulated major ECM protein of $70-90 \mathrm{kDa}$, identified as integrin $\alpha 8 \beta 1$ ligand involved in kidney development [7-9]. The physiological functions of nephronectin is poorly understood, it is thought to play a role in epithelial-mesenchymal interactions via binding to $\alpha 8 \beta 1$ integrin, thus transmitting signals across the basement membrane $[7,10]$.

Other integrin ligands, including fibronectin and osteopontin, fail to compensate for nephronectin deficiency in the developing kidneys suggesting that nephronectin is a mandatory $\alpha 8 \beta 1$ integrin ligand required for epithelial-mesenchymal interactions. Moreover, nephronectin is the preferred $\alpha 8 \beta 1$ integrin ligand and the C-terminal side of its RGD motif serves as a synergistic site ensuring a specific 100-fold high affinity binding of nephronectin to $\alpha 8 \beta 1$ integrin $[11,12]$.

Podocytes are highly specialized post-mitotic terminally differentiated epithelial cells with numerous foot processes (FP) that have interdigitating pattern. Those FP are adherent to the outer layer of the glomerular basement membrane (GBM) while the cell body floats in Bowman's space [13].

FP integrity is mandatory to maintain the glomerular filtration barrier. Intact FP are fixed to the GBM by various integrin dimers and by $\alpha$ - and $\beta$-dystroglycans. Deletion of any of the integrins from podocytes has fatal consequences, most severe after deletion of $\alpha 3$ or $\beta 1$-integrin [13].

During glomerular injury, podocytes undergo several changes in their shape. The FP loose their regular interdigitating pattern (effacement) followed by loss of the space beneath the podocyte cell body then, finally by rearrangement of the cytoskeleton. This rearrangement includes formation of cytoskeletal mat closely apposed to the GBM, suggesting reorganization of the podocyte-GBM interactions [13].

FP effacement is the most prominent and the most enigmatic structural event occurring in many glomerulopathies. And the degree of proteinuria is dependent on the degree of FP effacement [14].

Finding novel biomarkers that can assess glomerular regeneration in response to steroid treatment will help to predict treatment failure as early as possible, avoid the unnecessary long duration of steroid treatment with its side effects and address the physician to early start other lines of treatment.

This study aimed to investigate nephronectin as a marker of glomerular regeneration in NS patients treated with corticosteroids and its probable use for differencing steroid responders from steroid-resistant patients.

\section{Patients and methods}

\section{Study population}

This case control study was carried out in the duration from June 2016 to August 2017. The study was conducted on 80 selected patients with NS collected from the pediatrics department, Tanta university hospital, Egypt. Forty healthy controls of matching age and sex were also enrolled from the outpatient Clinique. An informed written consent was obtained from the parents of all participants. The study was approved by the local ethical committee of faculty of medicine Tanta University and the research is complied with Helsinki Declaration.

At the time of diagnosis all patients were subjected to complete history taking with special attention to recent skin and throat infections, fever, drug administration, and any change of urine color. Patients were also subjected to physical examination to document fever, edema, ascites, nutritional status, volume status, and hypertension. The laboratory data including; complete blood count, antiSterptolysin O titre (ASOT), Serum Creatinine (Scr), eGFR using Schwartz equation, cholesterol, albumin, $24 \mathrm{~h}$ urine protein, complete urine analysis, and UACR were also collected.

\section{Patients characteristics}

NS was diagnosed by the triad of heavy proteinuria ( $>3 \mathrm{gm} /$ day), hypoalbuminemia, and edema. The steroid-sensitive nephrotic syndrome (SSNS) group included 40 patients who responded to steroid treatment within 6 weeks. The SRNS group included 40 patients who showed persistent protienuria after 6 weeks of corticosteroid treatment.

The patients were retrospectively selected upon the outcome of 6 weeks of corticosteroid treatment. All patients received the same dose of corticosteroid for 6 weeks (prednisolone $2 \mathrm{mg} / \mathrm{kg} /$ day), ACE inhibitors were only given to patients with hypertension.

Patients with history of infection, high ASOT, hematuria, fever, protein energy malnutrition, and autoimmune diseases were excluded.

\section{Samples collection and biochemical analysis}

Blood samples were collected in VACUETTE $^{\circledR}$ Blood Collection Tubes (Greiner Bio-One, Austria). Serum samples were collected in serum separating tubes and separated by centrifugation at $10000 \times g$ for $10 \mathrm{~min}$. Scr, cholesterol, and albumin were measured using automated chemistry analyzer (Konelab Prime-60i, Vantaa, Finland). NPNT concentration was measured by ELISA. Samples designed for RNA extraction were collected on EDTA. $24 \mathrm{~h}$ urine 
protein excretion was determined only once at the diagnosis; screened using 3\% sulphosalsylic acid, and confirmed by immune-turbidimetric method (BioSystems, Spain) then the patients were followed up by morning sample UACR.

\section{Assay of serum NPNT levels}

NPNT concentrations were measured using Enzyme-linked Immunosorbent Assay kit for Nephronectin (USCN life science, cat no. SEH522Hu, Houston, USA) according to manufacturer's instructions.

The kit applies the sandwich immunoassay technique; the provided microtiter plate is pre-coated with an antibody specific to NPNT. Standards and samples were added with the biotin-conjugated anti-NPNT to the microtiter plate wells. After $1 \mathrm{~h}$ of incubation at $37^{\circ} \mathrm{c}$, all the fluids in the well were discarded, and then the Avidin conjugated to Horseradish Peroxidase (HRP) was added to all wells. The plate was incubated again for another $30 \mathrm{~min}$, and then washed to remove excess unbound biological materials. After TMB substrate solution addition; only the wells containing NPNT, biotin-conjugated antibody, and enzymeconjugated Avidin exhibited change in color. The enzymesubstrate reaction was terminated by the addition of sulphuric acid stop solution and the color change was measured spectrophotometrically at a wavelength of $450 \mathrm{~nm}$ (Tecan Spectra II Microplate Reader, Hombrechtikon, Switzerland).

Curve expert 1.40 software was used to generate the standard curve by plotting the mean optical density (O.D) of each standard against its concentration and drawing the best fit curve. The concentration of NPNT in the samples was then determined by comparing its O.D to the standard curve.

\section{Assay of NPNT mRNA expression levels}

Quantitative real-time PCR analysis was used to measure NPNT gene expression. RNA was extracted from $1 \mathrm{ml}$ EDTA blood using Qiamp RNA Blood Mini Kit (Qiagen $\mathrm{GmbH}$, Germany), according to the manufacturer's instructions. RNA was extracted immediately after sample collection and its concentration and quality were measured using NanoDrop 2000 (Thermoscientific, USA). Three hundred nanograms of RNA were utilized to synthesize cDNA using HiSenScript ${ }^{\mathrm{TM}}$ RH [-] cDNA synthesis kit (iNtRON biotechnology, Korea) according to the manufacturer's instructions. cDNA was stored in cryotubes at $-80^{\circ} \mathrm{C}$ till the expression experiment time.

TaqMan real-time quantitative PCR amplification reactions were carried out with step one Real-Time PCR System (Applied Biosystems) using TaqMan Universal PCR Master Mix (Applied Biosystems, Foster city,
California, USA). The reaction mixture contained about 30 ng cDNA, $1 \mu \mathrm{L}$ Taqman assay ${ }^{\circ}$, and $10 \mu \mathrm{L} 2 \times$ TaqMan Buffer (Applied Biosystems, Foster city, California, USA) in a total reaction volume of $20 \mu \mathrm{L}$ under standard conditions (initial setup $2 \mathrm{~min}$ at $50^{\circ} \mathrm{C}, 10 \mathrm{~min}$ at $95^{\circ} \mathrm{C}, 40$ cycles of (denaturation for $15 \mathrm{~s}$ at $95^{\circ} \mathrm{C}$, annealing for $1 \mathrm{~min}$ at $60^{\circ}$ C).

After validation, GAPDH was used as internal control gene. All reactions were executed in duplicate. In the case of negative control, cDNA was not added. The cycle threshold (CT) values were used for normalized relative quantitation of the NPNT expression. The relative concentration of NPNT gene expression in each sample was calculated on basis of CT corrected by GAPDH expression $\mathrm{CT}$ in the same sample using the comparative method formula $2^{-\Delta \Delta} \mathrm{CT}$.

\section{Statistical analysis}

The data were presented as means $\pm \mathrm{SD}$ and as frequencies and percentages when appropriate. Kruskal-Wallis test and Chi X2 test were used for the comparison of numerical and non-numerical data, respectively. Receiver operator characteristic (ROC) curves were constructed to assess sensitivity, specificity, and respective area under the curve. The optimum cutoff value was investigated by maximizing both sensitivity and specificity and minimizing the distance from the left upper corner of the ROC curves. Pearson correlation was run to study the correlation between NPNT gene expression, its serum level and the laboratory findings. Regression analysis was performed to assess the studied parameter as potential predictors of steroid resistance. The statistical analysis was performed using IBM SPSS statistics 19 for windows. $P$ values less than 0.05 were considered statistically significant.

\section{Results}

The study was carried out over 15 months; 80 selected patients with NS were enrolled in addition to 40 healthy controls. Forty patients had SSNS and 40 had SRNS.

In the SSNS group the mean of patients ages was $8.3 \pm$ $3.7,62.5 \%$ of them were males, all of them had generalized edema, and only $2(5 \%)$ of them were hypertensive. In the SRNS group the mean of patients' ages was $6.8 \pm$ $4.2,40 \%$ of them were males, all of them had generalized edema, and $45 \%$ of them were hypertensive. In control group, the mean of their ages was $6.3 \pm 3.8$ and $57.5 \%$ of them were males. Comparing the means of age among SSNS, SRNS patients and controls no statistically significant difference was found between them $(P$ values 
Table 1 Summary of the clinical and laboratory data of the studied groups

\begin{tabular}{|c|c|c|c|}
\hline & SSNS & SRNS & Controls \\
\hline Age $($ mean \pm SD $)$ & $8.3 \pm 3.7$ & $6.8 \pm 4.2$ & $6.3 \pm 3.8$ \\
\hline \multicolumn{4}{|l|}{$\operatorname{Sex} n(\%)$} \\
\hline Male & $26(62.5 \%)$ & $16(40 \%)$ & $23(57.5 \%)$ \\
\hline Female & $14(37.5 \%)$ & $24(60 \%)$ & $17(42.5 \%)$ \\
\hline Edema $n(\%)$ & $40(100 \%)$ & $40(100 \%)$ & $0(0 \%)$ \\
\hline Hypertension $n(\%)$ & $2(5 \%)$ & $18(45 \%)^{\mathrm{a}}$ & $0(0 \%)$ \\
\hline $\begin{array}{l}\text { Serum creatinine }(\mathrm{mg} / \mathrm{dl}) \\
(\text { mean } \pm \mathrm{SD})\end{array}$ & $0.8 \pm 0.28$ & $1.0 \pm 0.38^{\mathrm{a}}$ & $0.8 \pm 0.36$ \\
\hline $\begin{array}{l}\text { Serum albumin }(\mathrm{mg} / \mathrm{dl}) \\
(\text { mean } \pm \mathrm{SD})\end{array}$ & $2.21 \pm 0.53$ & $\begin{array}{l}2.61 \pm \\
0.32^{\mathrm{a}}\end{array}$ & $3.8 \pm 0.28$ \\
\hline $\begin{array}{l}\text { Serum cholesterol (mgldl) } \\
(\text { mean } \pm \text { SD })\end{array}$ & $312 \pm 90.8$ & $\begin{array}{l}438.2 \pm \\
110.3^{\mathrm{a}}\end{array}$ & $68.7 \pm 21.3$ \\
\hline $\begin{array}{l}\text { UACR gm/gm (mean } \pm \\
\text { SD) }\end{array}$ & $4.14 \pm 0.79$ & $\begin{array}{l}4.72 \pm \\
0.96^{\mathrm{a}}\end{array}$ & $\begin{array}{l}0.107 \pm \\
0.032\end{array}$ \\
\hline $\begin{array}{l}\text { eGFR } \mathrm{ml} / \mathrm{min} / 1.73 \mathrm{~m} 2 \\
(\text { mean } \pm \mathrm{SD})\end{array}$ & $88 \pm 13.8$ & $\begin{array}{l}71.3 \pm \\
14.57^{\mathrm{a}}\end{array}$ & $84.38 \pm 12.1$ \\
\hline
\end{tabular}

SSNS steroid-sensitive nephrotic syndrome, SRNS steroid-resistant nephrotic syndrome, $U A C R$ urinary albumin/creatinine ratio, $e G F R$ estimated glomerular filtration rate.

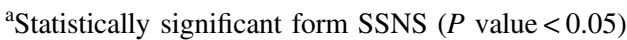

were $>0.05)$. The demographic, clinical and laboratory data are all summarized in Table 1.

The comparison of SSNS and SRNS patients' clinical findings showed a statistically significant difference regarding the incidence of hypertension, which was evidently higher in the SRNS group $(P$ value $<0.001)$. Also, comparison of the laboratory findings showed statistically significant differences between SSNS and SRNS regarding serum creatinine, eGFR, albumin, cholesterol, and urinary ACR. $P$ values were $0.009,<0.001,0.001,0.001$, and 0.004 , respectively.

Renal biopsies from patients with SRNS revealed that four of them had MCD; the majority (18/40) had focal segmental glomerulosclerosis(FSGS), (12/40) had membranous glomerulonephritis (MN), (5/40) had membranoproliferative glomerulonephritis (MPGN), and one patient showed non conclusive histological findings

Evident higher levels of NPNT mRNA expression were found in the SSNS patients. The means of NPNT gene expression in SSNS, SRNS, and controls were 10.82 \pm 7.39 , $1.19 \pm 0.94$, and $1.04 \pm 0.10$, respectively. The comparison of these means revealed statistically significant differences between SSNS and SRNS and also between SSNS and controls $(P$ values were both $<0.001)$. No significant difference was found between SRNS and the control $(P$ 0.322). Moreover, NPTN serum level were evidently higher in the SSNS patients. The means of NPTN serum levels were $4.64 \pm 3.05,0.69 \pm 0.44$, and $1.63 \pm 0.59$ in SSNS, SRNS, and controls, respectively. Comparison of these means
Table 2 Case summaries and comparison of NPNT expression and serum level results among the 3 studied groups

\begin{tabular}{|c|c|c|c|c|}
\hline & $\begin{array}{l}\text { SSNS } \\
\text { group } \\
(n=40)\end{array}$ & $\begin{array}{l}\text { SRNS } \\
\text { group } \\
(n=40)\end{array}$ & $\begin{array}{l}\text { Control } \\
\text { group } \\
(n=40)\end{array}$ & $P$ value \\
\hline $\begin{array}{l}\text { NPNT expression } \\
(\text { mean } \pm \text { SD) }\end{array}$ & $\begin{array}{l}10.82 \pm \\
7.39^{\mathrm{a}, \mathrm{c}}\end{array}$ & $\begin{array}{l}1.19 \pm \\
0.94^{\mathrm{b}}\end{array}$ & $1.04 \pm 0.10$ & $<0.001$ \\
\hline $\begin{array}{l}\text { NPNT serum level } \\
(\mathrm{ng} / \mathrm{ml})(\text { mean } \pm \text { SD) }\end{array}$ & $\begin{array}{l}4.64 \pm \\
3.05^{\mathrm{a}, \mathrm{c}}\end{array}$ & $\begin{array}{l}0.69 \pm \\
0.44^{\mathrm{b}, \mathrm{c}}\end{array}$ & $\underset{a, b}{1.63 \pm 0.59}$ & $<0.001$ \\
\hline
\end{tabular}

${ }^{\text {a }} P$ value $<0.05$ (significant) compared to steroid-resistant nephrotic syndrome (SRNS)

${ }^{\mathrm{b}} P$ value $<0.05$ (significant) compared to steroid-sensitive nephrotic syndrome (SSNS)

${ }^{\mathrm{c}} P$ value $<0.05$ (significant) compared to control

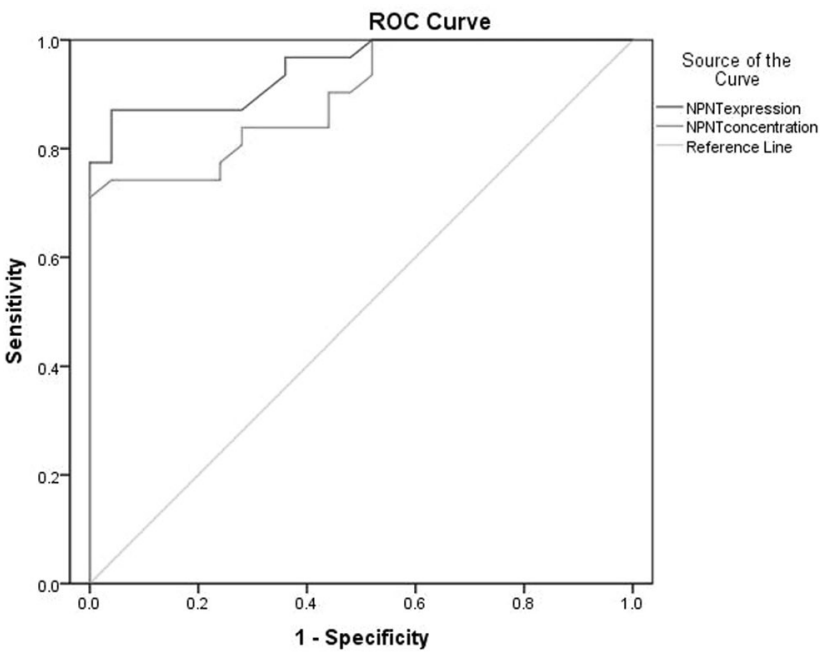

Fig. 1 ROC curves of NPNT expression and NPNT level

showed statistically significant differences between SSNS and SRNS, SSNS, and controls and also between SRNS and the control $(P$ values were all $<0.001)$. (Table 2$)$

ROC curve analyses were performed to study the diagnostic performance of NPNT expression and NPNT serum level and their ability to differentiate SSNS from SRNS. For the NPNT expression the optimum cutoff was $\geq 2.495$ $($ AUC $=0.948(0.895-1) ; 95 \% \quad C I$; sensitivity $=87.1 \%$; specificity $=92 \% ; P<0.001)$. For NPNT serum level the optimum cutoff was $\geq 1.215 \mathrm{ng} / \mathrm{ml} \quad$ (AUC $=0.896$ $(0.817-0.975) ; 95 \% \mathrm{CI}$; sensitivity $=74.2 \%$; specificity $=$ 92\%; $P<0.001$ ). (Fig. 1)

Pearson correlation was run (two-tailed) to correlate NPNT expression and serum level to the other laboratory findings of NS such as serum creatinine, albumin, cholesterol, and urine ACR. (Table 3)

For NPNT expression; significant positive correlation was observed between NPNT expression and its serum level $(r=0.801, P<0.001)$, significant negative correlation with urinary ACR was also found $(r=-0.602, P=0.002)$, and 
Table 3 Correlation matrix of nephronectine (NPNT) expression and its serum level in relation to other variables

\begin{tabular}{|c|c|c|c|c|c|c|c|c|}
\hline & & $\begin{array}{l}\text { NPNT } \\
\text { expression }\end{array}$ & $\begin{array}{l}\text { NPNT serum } \\
\text { level }\end{array}$ & UACR & $\begin{array}{l}\text { Serum } \\
\text { cholesterol }\end{array}$ & $\begin{array}{l}\text { Serum } \\
\text { albumin }\end{array}$ & $\begin{array}{l}\text { Serum } \\
\text { createnine }\end{array}$ & eGFR \\
\hline \multirow[t]{2}{*}{ NPNT expression } & Pearson $[r]$ & 1 & 0.801 & -0.602 & -0.311 & 0.334 & 0.018 & 0.203 \\
\hline & Sig. ( $P$ value $)$ & & $0.000^{\mathrm{b}}$ & $0.02^{\mathrm{a}}$ & 0.094 & 0.071 & 0.913 & 0.823 \\
\hline \multirow[t]{2}{*}{ NPNT serum level } & Pearson $[r]$ & 0.801 & 1 & -0.403 & -0.203 & 0.152 & 0.036 & 0.311 \\
\hline & Sig. ( $P$ value $)$ & $0.000^{\mathrm{b}}$ & & $0.04^{\mathrm{a}}$ & 0.283 & 0.422 & 0.85 & 0.094 \\
\hline \multirow[t]{2}{*}{ UACR } & Pearson $[r]$ & -0.602 & -0.403 & 1 & 0.274 & -0.426 & 0.037 & -0.12 \\
\hline & Sig. ( $P$ value $)$ & $0.02^{\mathrm{a}}$ & $0.04^{\mathrm{a}}$ & & 0.143 & $0.019^{\mathrm{a}}$ & 0.847 & 0.527 \\
\hline \multirow[t]{2}{*}{ Serum cholesterol } & Pearson $[r]$ & -0.311 & -0.203 & 0.274 & 1 & -0.541 & 0.168 & -0.183 \\
\hline & Sig. ( $P$ value $)$ & 0.094 & 0.283 & 0.143 & & $0.042^{\mathrm{a}}$ & 0.632 & 0.334 \\
\hline \multirow[t]{2}{*}{ Serum albumin } & Pearson $[r]$ & 0.334 & 0.152 & -0.426 & -0.541 & 1 & -0.237 & 0.248 \\
\hline & Sig. ( $P$ value $)$ & 0.071 & 0.422 & $0.019^{\mathrm{a}}$ & $0.042^{\mathrm{a}}$ & & 0.207 & 0.193 \\
\hline \multirow[t]{2}{*}{ Serum Createnine } & Pearson $[r]$ & 0.018 & 0.036 & 0.037 & 0.168 & -0.237 & 1 & -0.786 \\
\hline & Sig. $(P$ value $)$ & 0.913 & 0.85 & 0.847 & 0.632 & 0.207 & & $0.012^{\mathrm{a}}$ \\
\hline \multirow[t]{2}{*}{ eGFR } & Pearson $[r]$ & 0.203 & 0.311 & -0.12 & -0.183 & 0.248 & -0.786 & 1 \\
\hline & Sig. $(P$ value $)$ & 0.823 & 0.094 & 0.527 & 0.334 & 0.193 & $0.012^{\mathrm{a}}$ & \\
\hline
\end{tabular}

NPNT Nephronectin, UACR urinary albumin/creatinine ratio, eGFR estimated glomerular filtration rate, $r$ Pearson correlation coefficient

${ }^{\mathrm{a}}$ Correlation is significant at 0.05 (two-tailed)

${ }^{\mathrm{b}}$ Correlation is significant at the 0.01 level (two-tailed)

Table 4 Multiple linear regression analysis for NPNT as potential predictors of steroid resistance among nephrotic syndrome patients

\begin{tabular}{llllll}
\hline & \multicolumn{2}{l}{$\begin{array}{l}\text { Unstandardized } \\
\text { coefficients }\end{array}$} & $\begin{array}{l}\text { Standardized } \\
\text { coefficients }\end{array}$ & $t$ & $P$ value \\
\hline B & Std. Error & $\beta$ & & \\
NPNT expression & -0.027 & 0.009 & -0.395 & -3.010 & $0.004^{*}$ \\
NPNT concentration & -0.068 & 0.021 & -0.408 & -3.175 & $0.003^{*}$ \\
\hline$P$ value $<0.05$ (significant) & & &
\end{tabular}

Glomerular filtration barrier repair may include increased expression of the proteins responsible for signal transduction and the interaction between glomerular cells and the surrounding ECM including NPNT.

This work showed that NPNT mRNA expression and NPNT serum levels were significantly higher in SSNS than in SRNS. The enhanced NPNT gene expression with subsequent elevated serum level during recovery in SSNS patients indicates its role in nephron regeneration. On the other hand, in SRNS, the expression of NPNT was not enhanced by corticosteroid treatment. The lower serum levels of NPNT in SRNS than controls may be attributed to its loss in urine with the massive proteinuria. These findings may suggest NPNT as a possible differentiating biomarker between SSNS from SRNS.

To our knowledge this is the first study to assess NPNT as a biomarker to differentiate SSNS from SRNS, however, many studies had been performed investigating its role in renal development and regeneration after kidney injuries $[12,16,17]$.

Enhanced NPNT expression in SSNS patients may agree with Müller-Deile et al., 2017, who showed that the reduced 
glomerular levels of NPNT is a novel probable mechanism for proteinuria development in active glomerular diseases [18].

Also, our findings are in agreement with Kashani et al.; 2015, who reported NPNT as one of the novel biomarkers that indicate kidney repair after acute kidney injury; however, they recommended further investigations to verify its performance in the clinical setting [19].

Moreover, Cheng et al., 2008 declared enhanced expression of NPNT in regenerating nephrons in an experimental model during recovery from acute kidney injury [17].

Linton et al., 2007 reported that nephronectin is essential for kidney development through integrin $\alpha 8 \beta 1$-mediated stimulation of glial cell line-derived neurotrophic factor (GDNF) expression. And, they also showed that the lack of functional NPNT in embryos is associated with kidney agenesis or hypoplasia [12].

Nakatani et al., 2012 studied Nephronectin expression in glomeruli from various kidney diseases. They reported its lower expression in almost all active glomerular diseases: lupus nephritis, membranous glomerulonephritis, IgA glomerulonephritis, proliferative glomerulonephritis, crescentic glomerulonephritis, amyloidosis, light chain deposition disease, and many other kidney diseases, such as segmental glomerulosclerosis and hypertensive nephropathy [20].

Soluble urokinase plasminogen activator receptor (suPAR) has been the most extensively studied biomarker of SRNS. However, contradictory results had been declared. In 2015, Peng Z et al., showed that serum suPAR may help to differentiate steroid resistance from steroid-sensitive NS in children with high specificity but low sensitivity [21].

NPNT is the preferred $\alpha 8 \beta 1$ integrin ligand and mice models deficient in NPNT showed similar phenotype to those with $\alpha 8 \beta 1$ integrin deficiency [12]. uPAR acts through the activation of podocyte $\beta 3$-integrin signaling. $\beta 3$-integrin activation is associated loss of podocyte $\alpha 3$ and $\alpha 5$ integrins with subsequent podocyte effacement and detachment from the GBM [22]. Because $\alpha 3$ and $\beta 1$ are the most important integrins involved in podocytes effacement, likely, combined NPNT and suPAR estimation may give promising results.

Although FSGS is the most common pathological condition causing SRNS, the underling pathology of SRNS includes a variety of other disease conditions. Since 2013, many studies had suggested UPAR as marker of FSGS. However, their findings have been extremely controversial [23-31].

Wei et al., showed elevated suPAR concentrations in primary FSGS compared to healthy controls and to patients with MCD in both children and adults and defined a threshold of $3000 \mathrm{pg} / \mathrm{ml}$ might distinguish FSGS from other glomerulopathies [26]. Also, $\mathrm{Li}$ et al. found UPAR to be specifically elevated in some patients with FSGS compared to MCD and MN and suggested that suPAR assay may help to predict steroid response in patients with primary FSGS [27].

However, Schlöndorff showed that serum suPAR can not reliably distinguish FSGS from other proteinuric glomerular diseases and denied the validity of serum suPAR as a biomarker of primary or secondary FSGS [28]. Moreover, Sinha et al., Maas et al., Meijers et al., and Bock et al. also found that suPAR do not distinguish FSGS from other causes of NS [22, 29-31].

The present study demonstrated, for the first time, that Nephronectin may be a candidate biomarker differentiating SSNS from SRNS with promising sensitivity and specificity. However, due to the relative small sample size used in this study; further studies with larger number of samples are recommended.

Acknowledgements Many thanks go to El-askary E. and Mabrouk A.; assistant lecturers of pediatrics for their great help in the selection and the follow up of the patients. Also, we are very grateful to the parents of all participants; this work would have never been accomplished without their help and understanding.

\section{Compliance with ethical standards}

Conflict of interest The authors declare that they have no conflict of interest.

\section{References}

1. Indian Society of Pediatric N, Gulati A, Bagga A, Gulati S, Mehta KP, Vijayakumar M. Management of steroid resistant nephrotic syndrome. Indian Pediatr. 2009;46:35-47.

2. Chua A, Yorgin P Steroid-Resistant Nephrotic Syndrome. Evidence-Based Nephrology (Wiley-Blackwell, New Jersey, 2009). p. 787-805.

3. Gipson DS, Massengill SF, Yao L, Nagaraj S, Smoyer WE, Mahan JD, et al. Management of childhood onset nephrotic syndrome. Pediatrics. 2009;124:747-57.

4. Banerjee S. Steroid resistant nephrotic syndrome. Indian J Pediatr. 2002;69:1065-9.

5. Pozzi A, Zent R. Integrins in kidney disease. J Am Soc Nephrol. 2013;24:1034-9.

6. Hynes RO. Integrins: bidirectional, allosteric signaling machines. Cell . 2002;110:673-87.

7. Brandenberger R, Schmidt A, Linton J, Wang D, Backus C, Denda $\mathrm{S}$, et al. Identification and characterization of a novel extracellular matrix protein nephronectin that is associated with integrin alpha 8 beta 1 in the embryonic kidney. J Cell Biol. 2001;154:447-58.

8. Muller U, Wang D, Denda S, Meneses JJ, Pedersen RA, Reichardt LF. Integrin alpha8beta1 is critically important for epithelialmesenchymal interactions during kidney morphogenesis. Cell. 1997;88:603-13.

9. Morimura N, Tezuka Y, Watanabe N, Yasuda M, Miyatani S, Hozumi N, et al. Molecular cloning of POEM: a novel adhesion molecule that interacts with alpha8betal integrin. J Biol Chem. $2001 ; 276: 42172-81$. 
10. Sun Y, Kuek V, Qiu H, Tickner J, Chen L, Wang H, et al. The emerging role of NPNT in tissue injury repair and bone homeostasis. J Cell Physiol. 2017;9999:1-8.

11. Sato Y, Uemura T, Morimitsu K, Sato-Nishiuchi R, Manabe R, Takagi J, et al. Molecular basis of the recognition of nephronectin by integrin alpha8beta1. J Biol Chem. 2009;284:14524-36.

12. Linton JM, Martin GR, Reichardt LF. The ECM protein nephronectin promotes kidney development via integrin alpha8beta1mediated stimulation of Gdnf expression. Development. 2007;134:2501-9.

13. Kriz W, Shirato I, Nagata M, LeHir M, Lemley KV. The podocyte's response to stress: the enigma of foot process effacement. Am J Physiol Ren Physiol. 2013;304:F333-47.

14. Chang J-w, Pardo V, Sageshima J, Chen L, Tsai H-L, Reiser J, et al. Podocyte foot process effacement in post-reperfusion allograft biopsies correlates with early recurrence of proteinuria in focal segmental glomerulosclerosis. Transplantation. 2012;93: $1238-44$

15. Hiranuma K, Yamada A,Kurosawa T,Aizawa R,Suzuki D, et al. Expression of nephronectin is enhanced by 1 a,25-dihydroxy vitamin D 3. FEBS Open Bio. 2016;6:914-8.

16. Miner JH. Mystery solved: discovery of a novel integrin ligand in the developing kidney. J Cell Biol. 2001;154:257-60.

17. Cheng CW, Ka SM, Yang SM, Shui HA, Hung YW, Ho PC, et al. Nephronectin expression in nephrotoxic acute tubular necrosis. Nephrol Dial Transplant. 2008;23:101-9.

18. Muller-Deile J, Dannenberg J, Schroder P, Lin MH, Miner JH, Chen $\mathrm{R}$, et al. Podocytes regulate the glomerular basement membrane protein nephronectin by means of miR-378a-3p in glomerular diseases. Kidney Int. 2017;92:836-49.

19. Kashani KK, John A. Novel biomarkers indicating repair or progression after acute kidney injury. Curr Opin Nephrol Hypertens. 2015;24:21-7.

20. Nakatani S, Ishimura E, Mori K, Fukumoto S, Yamano S, Wei M, et al. Nephronectin expression in glomeruli of renal biopsy specimens from various kidney diseases: nephronectin is expressed in the mesangial matrix expansion of diabetic nephropathy. Nephron Clin Pract. 2012;122:114-21.
21. Peng Z, Mao J, Chen X, Cai F, Gu W, Fu H, et al. Serum suPAR levels help differentiate steroid resistance from steroid-sensitive nephrotic syndrome in children. Pediatr Nephrol. 2015;30:301-7.

22. Maas RJ, Deegens JK, Wetzels JF. Serum suPAR in patients with FSGS: trash or treasure? Pediatr Nephrol. 2013;28:1041-8.

23. Reiser J, Wei C, Tumlin J. Soluble urokinase receptor and focal segmental glomerulosclerosis. Curr Opin Nephrol Hypertens. 2012;21:428-32.

24. Jin J, Li YW, He Q. Primary and recurrent focal segmental glomerulosclerosis closely link to serum soluble urokinase-type plasminogen activator receptor levels. Transplant Proc. 2015;47:1760-5.

25. Segarra A, Jatem E, Quiles MT, Arbos MA, Ostos H, Valtierra N, et al. [Diagnostic value of soluble urokinase-type plasminogen activator receptor serum levels in adults with idiopathic nephrotic syndrome]. Nefrologia. 2014;34:46-52.

26. Wei C, Trachtman H, Li J, Dong C, Friedman AL, Gassman JJ, et al. Circulating suPAR in two cohorts of primary FSGS. J Am Soc Nephrol. 2012;23:2051-9.

27. Li F, Zheng C, Zhong Y, Zeng C, Xu F, Yin R, et al. Relationship between serum soluble urokinase plasminogen activator receptor level and steroid responsiveness in FSGS. Clin J Am Soc Nephrol. 2014;9:1903-11.

28. Schlondorff D. Are serum suPAR determinations by current ELISA methodology reliable diagnostic biomarkers for FSGS? Kidney Int. 2014;85:499-501.

29. Sinha A, Bajpai J, Saini S, Bhatia D, Gupta A, Puraswani M, et al. Serum-soluble urokinase receptor levels do not distinguish focal segmental glomerulosclerosis from other causes of nephrotic syndrome in children. Kidney Int. 2014;85:649-58.

30. Bock ME, Price HE, Gallon L, Langman CB. Serum soluble urokinase-type plasminogen activator receptor levels and idiopathic FSGS in children: a single-center report. Clin J Am Soc Nephrol. 2013;8:1304-11.

31. Meijers B, Maas RJ, Sprangers B, Claes K, Poesen R, Bammens $\mathrm{B}$, et al. The soluble urokinase receptor is not a clinical marker for focal segmental glomerulosclerosis. Kidney Int. 2014;85: 636-40. 